\title{
Analysis of Enterprise Safety Production Governance Structure Based on Evolutionary Game
}

\author{
Hong-Xia Li ${ }^{a}$ and Ying-Ying Xin ${ }^{b}$ \\ School of Management, Xi'an University of Science and Technology, P.R. China \\ a406144519@qq.com, b1524635339@qq.com
}

Keywords: evolutionary game, safe production, corporate governance structure

\begin{abstract}
This article introduces the existing research and deficiencies of domestic and foreign scholars in the corporate governance of corporate safety production, as well as the application research based on evolutionary game theory in various fields. Based on evolutionary game theory, from the perspective of limited rationality and stakeholders, a systematic study of the corporate governance structure's behavior in safety production is proposed, so as to establish a multiparty dynamic game model of corporate governance structure for corporate safety production. Safety production provides a new perspective, reduces the occurrence of safety production accidents, and guarantees the orderly progress of safety production activities.
\end{abstract}

\section{Introduction}

Corporate governance refers to the system of checks and balances formed between the company's internal board of directors, the board of supervisors and the management level ${ }^{[1]}$. In view of the important influence of the board of directors, the board of supervisors and the managerial level on the safe production and operation of enterprises, domestic and foreign scholars have conducted in-depth research on the board of directors, board of supervisors and managers in the corporate governance structure under the framework of entrustment-agent. More fruitful research results. Representative research results are as follows: John $G$ etc. ${ }^{[2]}$ consider the factors of supervision, supervision cost and supervision success rate, establish a game-supervised game model of the board of directors, and find that high salary can better control the manager through calculation. Human behavior. In his book, Zhang Weiying ${ }^{[3]}$ established a supervisory cost function for managers' lazy behavior and non-slack behavior, and obtained the best supervision of the board of directors. Deng Yingjie etc ${ }^{[4]}$ built a monitoring cost model based on the goal of maximizing revenue and minimizing total cost, and analyzed the supervision model of the board of directors on the behavior of state-owned enterprise managers. Yao Haixin etc ${ }^{[5]}$ used the game theory analysis method to analyze the supervision function of the board of directors from the perspective of active supervision. The study found that the board of directors played an active supervisory function to promote the growth of the company's value and protect shareholders' rights and interests. $\mathrm{Yu}$ Dong ${ }^{[6]}$ comprehensively considers the influence of manager abuse of power and board supervision on company performance and shareholder returns, constructs a game model, verifies the effectiveness of board supervision on managers, and finds a game equilibrium between board and managers. Hu Can etc ${ }^{[7]}$ based on the determination of the behavior selection strategy of the board of directors, the management level and the board of supervisors, comprehensively consider the factors of wages, supervision, business performance and other factors, and build a complete information static game model of the board of directors, the management level and the board of supervisors, research board, managerial and supervisory board members' behavior selection strategies. Zhong Ziliang ${ }^{[8]}$ established a game model between the board of directors, the managerial level and the board of supervisors, and analyzed the impact of the supervision of the board of supervisors on the fraud of the management and the board of directors. Hou Xiangyin ${ }^{[9]}$ regards the board of directors and the manager as the game object of the board of supervisors, and comprehensively considers the factors of fraud probability, fraud income, fraud cost, penalty loss and other factors to establish a game model, and study the behavior selection strategy of the board of directors, the manager and the 
board of supervisors.

However, most of the existing literatures establish a static game model under the framework of principal-agent, and do not discuss the evolution trend of corporate governance structure interest group behavior. This is based on the evolutionary game theory. From the perspective of bounded rationality and stakeholders, the evolutionary game model of building a safe production governance structure provides a research space.

\section{Status Quo of Game Analysis Research on Corporate Governance Issues at Home and Abroad}

\subsection{The status quo of game analysis research on foreign corporate governance issues}

The first time the game model was used was the French economist Cournot (1838), who established an oligopolistic game model. Modern game theory began in Von Neumann and Morgenstern in 1944, "Game Theory and Economic Behavior." Von Neumann proposed many concepts of game theory and the standard form of game theory, which proved that there are general maximum and minimum solutions for the finite double zero-sum game. A major development in game theory was the four papers published by John Nash between 1950 and 1953. These four papers laid the foundation for cooperative games, bargaining theory and non-cooperative game theory. Nash proved the existence of non-cooperative game solution, and proposed the concept Nash equilibrium of the foundation of game theory, which proved the existence of Nash bargaining problem solution. Game theory has developed rapidly after Nash. In 1965, R. Selten proposed the concept of refined Nash equilibrium, introducing Nash equilibrium into dynamic analysis. Between 1967 and 1968, John Harsanyi introduced incomplete information into the study of game theory, which laid the theoretical foundation for information economics. The 1994 Nobel Prize in Economics was awarded to the three economists. Many economists have made important contributions to the development of game theory. For example, Lloyd Shapley (1953) first studied the random game problem; HWKuhn (1953) proposed the extension of the game; RJ Aumann (1974) proposed the concept of correlation equilibrium. (correlated equilibrium). Since the development of game theory, it has formed a cooperative game, non-cooperative game, random and dynamic game, bargaining theory, evolutionary game theory and other branches (according to JEL Classification System).

\subsection{Status quo of game analysis research on domestic corporate governance issues}

Zhang Xiuwu, Hu Ridong, Yan Xiuchun applied the complete information dynamic game model to analyze the behaviors of major shareholders, minority shareholders and regulatory authorities in the governance of listed companies. It is concluded that the probability of encroachment of large shareholders is inversely proportional to the punishment, and is proportional to the cost of supervision. The probabilities detected by the regulatory authorities are inversely proportional to the penalty factor, and the probability of minority shareholders' appeals is unrelated to the assumptions, and corresponding recommendations are made ${ }^{[10]}$. Zeng Yulin and Wang Fangyu analyzed the corporate governance structure of China's state-owned enterprises (including state-owned holding companies) through the analysis of the dynamic game of the asymmetry of the principal-agent relationship in the corporate governance structure, and from the sound game behavior subject Three aspects, such as constructing a repeating game operation mechanism and perfecting the enforceable punishment strategy, propose countermeasures to improve the corporate governance structure ${ }^{[11]}$. Jiao Xiaonan modeled the corporate governance problem as a principal-agent model, and established a shareholder governance model, a common governance model, and a state-owned corporate governance model. By solving the model and analyzing the main factors affecting corporate governance, the direction and approach to improve state-owned corporate governance are obtained $^{[12]}$.

\section{Evolutionary Game Method}

Evolutionary game theory, also called evolutionary game theory, is formed by the combination of biological evolution theory and game theory. It takes the participants of bounded rationality as the 
research object, and incorporates various factors affecting the behavior of participants into the model. It uses the viewpoint of system theory to analyze the dynamic evolution process of both sides of the game and examine the evolutionary trend of group behavior.

The method based on evolutionary game analysis and simulation is also suitable for studying the governance structure of enterprises in safety production. Firstly, the evolutionary game model between the "Board of Directors-Supervisory Board-Managers" is constructed, and the influencing factors affecting the evolutionary state of evolution and the dynamic evolution process of the players are analyzed, and the stable state characteristics of the evolutionary system are obtained. Secondly, according to the influencing factors, the parameter values are set, and the numerical experiment simulation is carried out by using MATLAB software to analyze the influence of parameter value changes on the choice of different gamers' behavior strategies. Finally, based on the an alysis of simulation results, the company's stakeholders effectively reduce the occurrence of safety production accidents, and put forward corresponding countermeasures and suggestions.

\section{Application of Evolutionary Game Method}

\subsection{Research on security management based on evolutionary game}

Some scholars have focused on environmental safety management. In view of the environmental protection problem, based on the evolutionary game theory, the authors study the complex game relationship between the government and the enterprise in the behavior strategy, and propose countermeasures to help the government and enterprises to strengthen environmental protection; some scholars focus on food safety management. In response to the safety supervision of food, third-party supervision was introduced to influence the results of the game between the two parties; some scholars focused on the safety supervision of coal mining enterprises. The evolutionary game theory is used to describe the interaction among stakeholders in China's coal mine safety supervision system, to explore the evolutionary stability strategy, and to reduce the occurrence of safety accidents through effective supervision.

\subsection{Research on enterprise technology innovation and organizational innovation based on evolutionary game}

In the aspect of enterprise technology innovation, scholars analyze the dynamic evolution process of enterprises in innovation, the dynamic evolution process of decision-making among inter-organizational resource sharing in technology innovation networks, and the impact of imitative innovation and independent innovation strategies on themselves and society through evolutionary game methods. and many more. In terms of organizational innovation, scholars use game theory to construct a game model of industry-university innovation, analyze the strategies of enterprises and governments in regional innovation, and the strategic choices of enterprises, universities, and research institutions under the influence of additional income distribution and cost sharing. The model stabilizes state changes.

\subsection{Research based on evolutionary games in other fields}

Some scholars based on evolutionary games to explain and predict the social and economic sustainability of the public health insurance supply chain; some scholars explored the evolution mechanism of regional industrial transfer in China based on China's industrial upgrading and sustainable development; some scholars Combining evolutionary game and system dynamics construction model is used to study the spread of manufacturing green supply chain management in China, and other fields.

\section{Conclusion}

It can be found from the above research status that scholars at home and abroad have achieved many achievements in corporate governance structure and evolutionary game, and some of the theories have achieved remarkable results in practice. However, in the analysis and research of 
enterprise safety production governance structure, it still needs to be analyzed in depth. At present, there are still some problems that need to be solved urgently. On the one hand, most of the current literature analyzes the game behavior among various stakeholders in the corporate governance structure, and systematically analyzes the corporate governance structure based on evolutionary game analysis in terms of safety production. Further research is needed. On the other hand, in the current corporate governance, the evolutionary game adopts the "complete rationality" hypothesis or the two-party game, and adopts the "limited rationality" hypothesis and multi-party game to construct the enterprise safety production governance structure model based on evolutionary game analysis. In line with the development of modern enterprise safety production. In response to this problem, it is necessary to use the method of evolutionary game analysis and simulation to reduce the occurrence of safety production accidents by constructing a multi-party game model of corporate governance structure.

\section{References}

[1] YE Chengang, GENG Li, ZHANG Lijuan. Corporate Governance Structure, Internal Control Quality and Corporate Financial Performance[J]. Audit Research, 2016(2): 104-112.

[2] AMOULD R J, FINNERTY J E. Wages, Supervision and Sharing [J]. Quarterly Review of Economics \& finance, 2008,48(4):653-672.

[3] Zhang Weiying. Property Rights, Incentives and Corporate Governance [M]. Beijing: Economics Press, 2005.

[4] Deng Yingjie, Li Jianhua. Research on the Behavior Supervision Mechanism of State-owned Enterprise Operators[J]. Systems Engineering, 2006, (9): 58-60.

[5] Yao Haixin, Zhao Lijuan, Sun Mengnan. Game analysis of active supervision by the board of directors [J/OL]. Finance and Accounting Monthly, 2017, (10): 10-13.

[6] YU Dong. Game Analysis of Board of Directors' Supervision over Managers' Control [J]. Journal of Shandong Agricultural Management Cadre College, 2005, (5): 158-159+10.

[7] Hu Can, Mao Meihua, Yu Fei. Game Analysis between Interests in Corporate Governance_- Taking the Game between Board of Directors, Board of Supervisors and Managers as an Example [J]. China Business, 2012, (25): 139- 140.

[8] Zhong Ziliang. Game Theory Analysis of Corporate Governance [J]. Productivity Research, 2015, (2): 186-188.

[9] Hou Xiangyin. Game Analysis of Corporate Governance [D]. Department of Business Administration and Economics, Tianjin University, 2010.

[10] Cao Yugui, Yang Zhongzhi. Game Analysis of Shareholders' Supervision Behavior in Corporate Governance. Journal of Northwest A\&F University, 2005(1): 80 84.

[11] Yan Xiaolong. Conflicts of Interest and Balance in Corporate Governance: [PhD thesis]. Hunan: Central South University, 2003.

[12] Zhang Xiuwu, Hu Ridong, Yan Xiuchun. Dynamic game analysis of large and small shareholders and regulatory authorities in the governance of listed companies. Information Economics and E-Commerce: Proceedings of the 13th China Information Economics Association Annual Conference, $2008: 152 \sim 155$. 